\title{
MINI-REVIEW
}

\section{Polymorphism of the Fc $\gamma$ receptor IIA and malaria morbidity}

Érika Martins Braga, ${ }^{1}$ Kézia Katiani Gorza Scopel, ${ }^{1}$ Natália Tiemi Komatsu, ${ }^{2}$ Mônica da SilvaNunes $^{2}$ and Marcelo Urbano Ferreira ${ }^{2 *}$

${ }^{1}$ Departamento de Parasitologia, Instituto de Ciências Biológicas, Universidade Federal de Minas Gerais, Av. Antônio Carlos 6627, Pampulha, 31270-901 Belo Horizonte (MG), Brazil. ${ }^{2}$ Departamento de Parasitologia, Instituto de Ciências Biomédicas, Universidade de São Paulo, Av. Prof. Lineu Prestes 1374, Cidade Universitária, 05508-900 São Paulo (SP), Brazil

${ }^{*}$ Correspondence to: Marcelo Urbano Ferreira, Email: muferrei@usp.br, Tel: + 5511 3091-7273, Fax: + 55 11 $3091-7417$

Journal of Molecular and Genetic Medicine (2005), 1(1), 5-10

(C) Copyright Érika Martins Braga et al

(Received 10 June 2005; Revised 11 July 2005; Accepted 11 July 2005; Available online 28 July 2005; Published 19 August 2005)

\begin{abstract}
Fc receptors (FcRs) are expressed on the surface of all types of cells of the immune system. They bind the Fc portion of immunoglobulin (Ig), thereby bridging specific antigen recognition by antibodies with cellular effector mechanisms. Fc $\gamma$ RIIA, one of the three receptors for human IgG, is a low-affinity receptor for monomeric IgG, but binds IgG immune complexes efficiently. Fc $\gamma$ RIIA is believed to play a major role in eliciting monocyte- and macrophage-mediated effector responses against blood-stage malaria parasites. A $\mathrm{G} \rightarrow$ A single nucleotide polymorphism, which causes an arginine $(\mathrm{R})$ to be replaced with histidine $(\mathrm{H})$ at position 131, defines two allotypes which difer in their avidity for complexed human $\operatorname{IgG}_{2}$ and $\operatorname{IgG}_{3}$. Because Fc $\gamma$ RIIA-H131 is the only Fc $\gamma \mathrm{R}$ allotype which interacts efficiently with human $\operatorname{IgG}_{2}$, this polymorphism may determine whether parasite-specific $\mathrm{IgG}_{2}$ may or may not elicit cooperation with cellular imune responses during blood-stage malaria infection. Here, we review data from four published case-control studies describing associations between Fc $\gamma$ RIIA R/H131 polymorphism and malaria-related outcomes and discuss possible reasons for some incongruities found in these available results.
\end{abstract}

KEYWORDS: Malaria, Fc receptors, polymorphism, IgG subclasses, case-control studies

\section{INTRODUCTION}

Fc receptors (FcRs) belong to the family of immunoreceptors, which includes T-cell receptors, B-cell receptors and natural killer (NK) receptors. These glycoproteins are expressed on the surface of all types of cells of the immune system; they bind the Fc portion of immunoglobulin (Ig), thereby bridging specific antigen recognition by antibodies with cellular effector mechanisms. The FcRs are essential molecules in the host defense against infection. Interaction between antibodies of a given class and the corresponding FcR elicits a variety of cellular responses, such as phagocytosis and endocytosis, antibody-dependent cell-mediated cytotoxicity (ADCC), generation of superoxide radicals and release of pro-inflammatory cytokines (Fleisch and Neppert, 2000). Specific FcRs are known for each class of human Ig, but Fc $\gamma$ RI (CD64), Fc $\gamma$ RII (CD32), Fc $\gamma$ RIII (CD16) and FceRI form a subset of more closely related molecules within the immunoglobulin superfamily (Kinet, 1999; Ravetch and Bolland, 2001; Monteiro and van der Winckel, 2003).

The three classes of human Fc $\gamma R$ s comprise several isoforms (Fc $\gamma$ RIA, -B and -C; Fc $\gamma$ RIIA, -B and -C, and Fc $\gamma$ RIIIA and -B), which differ in their binding affinity to different human IgG subclasses and levels of expression on different cell types. The low-affinity isoforms (FcrRIIA, -IIB, -IIC, -IIIA and -IIIB) co-localize to a region on chromosome 1q23 which includes the genes coding for C-reactive protein, a family of FcR homologues and the Duffy blood group (Su et al, 2002). Members of the Fc $\gamma$ RII class differ from those of other Fc $\gamma$ R classes in 
that they comprise either activitory (ITAM) or inhibitory (ITIM) signaling motifs within their respective ligandbinding chains (Gessner et al, 1998). Fc $\gamma$ RIIA is a lowaffinity receptor for monomeric $\operatorname{IgG}\left(\mathrm{K}_{\mathrm{A}}<10^{7} / \mathrm{M}\right)$, but binds IgG immune complexes efficiently. It is the most widely distributed $\mathrm{Fc} \gamma \mathrm{R}$ isoform, being expressed on the surface of virtually all myeloid cells, including mononuclear phagocytes, neutrophils and platelets. This receptor plays critical roles in the removal of immune complexes, activation of inflammatory cells and phagocytosis of antibody-coated microorganisms (Ravetch and Bolland, 2001).

\section{Fc $\gamma$ RIIA polymorphism}

Fc $\gamma$ RIIA displays a funcionally relevant $\mathrm{G} \rightarrow$ A single nucleotide polymorphism in the region encoding its ligand-binding domain, which causes an arginine (R) to be replaced with histidine $(\mathrm{H})$ at position 131 of its extracellular domain. Both allotypes avidly bind complexed human $\operatorname{IgG}_{3}$ and $\operatorname{IgG}_{1}$, but the FcyRIIA$\mathrm{H} 131$ allotype displays a higher affinity for human $\mathrm{IgG}_{2}$ and $\mathrm{IgG}_{3}$ than the FcyRIIA-R131 allotype; none of them bind $\mathrm{IgG}_{4}$ efficiently. Because FcrRIIA-H131 is the only Fc $\gamma \mathrm{R}$ which interacts efficiently with human $\mathrm{IgG}_{2}$, this allotype is essential for the clearance of $\operatorname{IgG}_{2}$ containing immune complexes (Salmon et al, 1996) and phagocytosis of $\mathrm{IgG}_{2}$-opsonised microorganisms (Sanders et al, 1995). As a consequence, the Fc $\gamma$ RIIA$\mathrm{R} / \mathrm{H} 131$ polymorphism is associated with predisposition to autoimmune diseases such as systemic lupus erythematosus and antiphospholipid syndrome, which may be mediated by the deposition of $\mathrm{IgG}_{2}$-containing immune complexes (Karassa et al, 2004), and infections caused by encapsulated bacteria, whose clearance largely depends on $\mathrm{IgG}_{2}$-mediated phagocytosis (Rodriguez et al, 1999; Jansen et al, 1999). A second polymorphic site has been described in FcyRIIA: a CA $\rightarrow$ GA mutation results in glutamine or tryptophan in its membrane-distal Ig-like domain. This amino acid replacement, however, does not affect the receptor avidity for IgG (Warmerdam et al, 1990).

The distribution of the FcyRIIA-H131 and -R131 allotypes vary widely among ethnic groups. H131/H131 homozygotes are more frequent among Eastern Asians than Caucasians (Lehrnbecher et al, 1999), being rare in Amazonian Amerindians (Kuwano et al, 2000). Differences in allotype frequencies of FcyRIIA-H131 and other linked genes are believed to account for part of the variation in the prevalence of some autoimmune and infectious diseases among ethnic groups.

\section{IgG subclasses and naturally acquired immunity to malaria}

Malaria parasites are major human pathogens associated with 300-500 million clinical cases worldwide and 0.53 million deaths each year, mostly among children under the age of five years living in sub-Saharan Africa (Guerin et al, 2002). Human malaria is caused by four species of parasitic protozoa of the genus Plasmodium: $P$. falciparum, $P$. vivax, $P$. malariae and $P$. ovale. The natural history of infection with $P$. falciparum, that causes most severe infections and nearly all malariarelated deaths, has been well characterised in areas of high endemicity in Africa (Day and Marsh, 1991). Infants have a primary malaria attack during their first year of life, while most toddlers and juveniles have already developed tolerance against severe disease, but still experience a few clinical episodes. African adolescents and adults, in contrast, are often clinically immune; they remain free of malaria symptoms despite continuous exposure to the parasite, but maintain lowgrade infections throughout the transmission season. Clinical immunity is usually lost during pregnancy, especially among primigravidae, or after migration to non-endemic areas. Life-long exposure to malaria parasites rarely leads to sterile immunity; blood-stage infections remain detectable by sensitive methods in all age groups.

The acquisition of immunity to blood-stage malaria parasites, after several years of continuous exposure to intense transmission, depends on both antibody- and cell-mediated mechanisms. The gradual switch towards Igs of both $\operatorname{IgG}_{1}$ and $\operatorname{IgG}_{3}$ subclasses, which bind efficiently to all classes and isoforms of $\mathrm{Fc} \gamma \mathrm{R}$ present on the surface of effector cells such as monocytes, macrophages and neutrophils, is believed to play a key role in this process. The binding of cytophilic antibodies to effector cells triggers parasite-killing effector responses, such as opsonisation and phagocytosis of extracellular parasites or parasitised red blood cells (pRBC) (Ferrante et al, 1990; Groux and Gysin, 1990) and the ADCC-like mechanism known as antibody-dependent cellular inhibition (ADCI) of intracellular parasites (Bouharoun-Tayoun et al, 1990) (Figure 1). Since both ADCI and the opsonising effect of cytophilic antibodies are competitively inhibited, in vitro, by non-cytophilic $\mathrm{IgG}_{2}$ and $\mathrm{IgG}_{4}$ antibodies with the same specificities (Groux and Gysin, 1990; Bouharoun-Tayoun and Druilhe, 1992), the subclass balance may be a decisive factor in naturally acquired immunity to malaria: protected and unprotected subjects could be differentiated by the relative levels of cytophilic antibodies recognising parasite antigens (Bouharoun-Tayoun and Druilhe, 1992; Ferreira et al, 1996).

Because ADCI is known to be mediated by Fc $\gamma$ RII (but not Fc $\gamma R I$ ) on the surface of monocytes (BouharounTayoun et al, 1995), Fc $\gamma$ RII polymorphisms that alter the affinity of this receptor for some IgG subclasses are expected to modulate the efficiency of monocyte-mediated parasite killing. Non-immune or partially immune subjects, for example, tend to produce predominantly IgG antibodies of the $\mathrm{IgG}_{2}$ subclass during acute malaria infections (Wahlgren et al, 1983; Ferreira et al, 1996), and this subclass bias has been associated with poor clinical immunity (Bouharoun-Tayoun and Druilhe, 1992). Although often regarded as blocking antibodies (Groux and Gysin, 1990; Bouharoun-Tayoun and Druilhe, 1992), these specific $\mathrm{IgG}_{2}$ antibodies might elicit both ADCI and phagocytosis by engaging effector cells carrying the Fc $\gamma$ RIIA-H131 allotype (Aucan et al, 2000). 

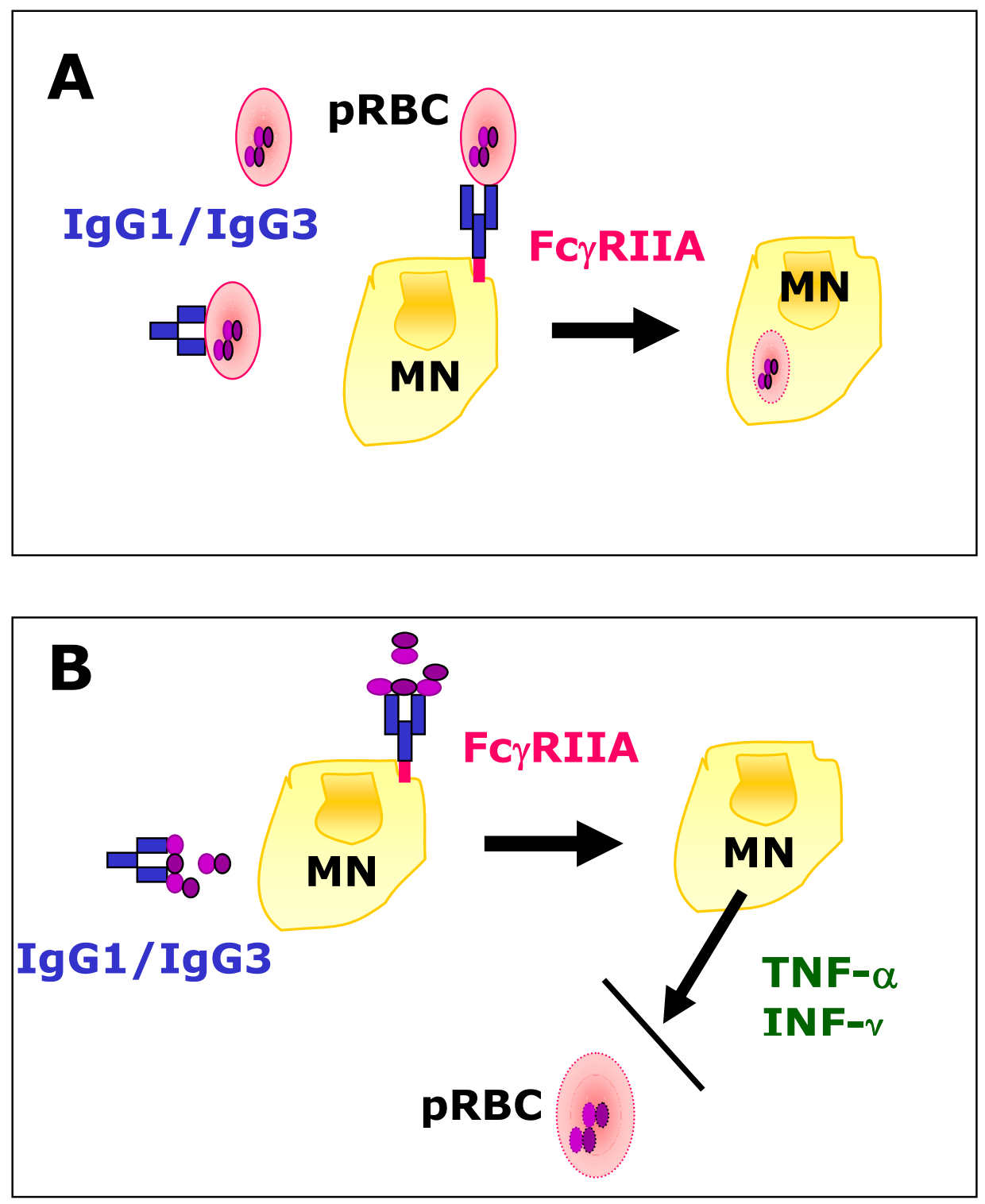

Figure 1. Antibody-dependent cellular mechanisms involved in Plasmodium falciparum blood stage killing. (A) Classical phagocytosis of parasitised red blood cells (pRBC). (B) Antibody-dependent cellular inhibition (ADCI). ADCI is an ADCC-like effect which inhibits the growth of young asexual blood-stages within erythrocytes through the release of soluble factors (such as tumour necrosis factor [TNF]- $\alpha$ and interferon [IFN]- $\gamma$ ) by monocytes (MN). This mechanism is triggered by the recognition of merozoite surface antigens by $\mathrm{IgG}$, which interacts with MN via their Fc $\gamma$ RIIA receptors. Panel B adapted from Druilhe and Pérignon (1997).

More than $70 \%$ of the African-American subjects so far typed are either homozygous or heterozygous for the H131 allele (Lehrnbecher et al, 1999); quite similar H131 allele frequencies have seen found in malaria-exposed African populations (Aucan et al, 2000; Shi et al, 2001; Cooke et al, 2003; Brouwer et al, 2004). An Fc $\gamma$ RIIA with increased affinity for human $\mathrm{IgG}_{2}$ and $\mathrm{IgG}_{3}$, in subjects carrying the H131 allele, implies that Fc $\gamma$ RIIA-dependent parasitekilling responses might be more efficiently elicited by specific antibodies of these subclasses. Accordingly, Fc $\gamma$ RIIA-mediated phagocytosis in vitro, following $\mathrm{pRBC}$ opsonisation with $\mathrm{IgG}_{3}$, is more efficient in human monocytes of the H131 allotype than in those of the R131 allotype (Tebo et al, 2002). Even more evident differences between Fc $\gamma$ RIIA allotypes are expected in relation to $\mathrm{IgG}_{2}$-mediated protection. In fact, $\mathrm{IgG}_{2}$ antibodies to surface malarial antigens confer significant protection against blood-stage infection and clinical disease in subjects carrying the H131 allele, but not in R131/R131 homozygotes (Aucan et al, 2000). If H131 allele carriers acquire $\mathrm{IgG}_{2}$-mediated protection from blood-stage infection before the exposure-dependent switch to specific 
antibodies of the $\mathrm{IgG}_{1}$ and $\mathrm{IgG}_{3}$ subclasses takes place, the Fc $\gamma$ RIIA-H131 allotype may be associated with a faster development of clinical immunity leading to reduced malaria morbidity in these subjects.

Accordingly, in a recent cross-sectional survey in Brazil we found higher levels of $\mathrm{IgG}_{2}$ subclass antibodies to locally prevalent variants of the major malaria-vaccine candidate antigen, merozoite surface protein-2 (MSP-2), among asymptomatic carriers of $P$. falciparum than in subjects with symptomatic malaria episodes due to the same species. Antibodies of all other IgG subclasses were found in similar concentrations in both clinical groups. Because of the high $\mathrm{H} 131$ allele frequency in the local population $(83 \%), \mathrm{IgG}_{2}$ antibodies to surface malaria antigens may help in triggering cell-mediated immunity to blood-stage parasites, via the FcyRIIA-H131 allotype, in the majority of these subjects (Scopel KKG and Braga EM, in preparation).

\section{FcrRIIA-H131 allotype and malaria morbidity}

Four published case-control studies have examined the association between H/R131 Fc $\gamma$ RIIA polymorphism and malaria morbidity in African and East-Asian populations (Table 1). Since different malaria-related outcomes were evaluated (high-density P. falciparum parasitaemia, severe malaria in children or adolescents and adults and placental malaria) in different ethnic and age groups, these studies are not strictly comparable. Significantly, however, none of them reported an association between Fc $\gamma$ RIIA-H131 allotype carriage and protection from malaria morbidity, as it could be expected on the basis of a putative $\mathrm{IgG}_{2}$ mediated protection against blood-stage parasites (Aucan et al, 2000). In contrast, R131/R131 homozygosity was associated with protection against high-density parasitaemia in one study (Shi et al, 2001) and H131/H131 homozygosity was associated with increased risk of either severe/cerebral malaria or placental malaria in three studies (Omi et al, 2002; Cooke et al, 2003; Brouwer et al, 2004).

Table 1. Characteristics and main findings of four published case-control studies addressing the association between Fc $\gamma$ RIIA polymorphism and Plasmodium falciparum malaria morbidity

\begin{tabular}{|c|c|c|c|}
\hline Country & Comparison groups & Main findings & Reference \\
\hline Kenya & $\begin{array}{l}\operatorname{High} \text {-risk } \\
\text { infants aged } 1 \text { year }\end{array}$ & $\begin{array}{l}\text { Significant excess of R131/R131 } \\
\text { homozygotes in the low risk group, when } \\
\text { compared to H131/R131 heterozygotes; } \\
\text { similar proportions of H131/H131 } \\
\text { homozygotes in both groups }\end{array}$ & Shi et al, 2001 \\
\hline Thailand & $\begin{array}{l}\text { Patients aged }>13 \text { years (mean, } 25 \text { years) } \\
\text { with either cerebral malaria }(n=107) \text {, non } \\
\text { cerebral severe malaria }(n=157) \text { or mild } \\
\text { malaria }(n=202)\end{array}$ & $\begin{array}{l}\text { Significant excess of } \mathrm{H} 131 / \mathrm{H} 131 \\
\text { homozygotes carrying the Fc } \gamma \text { RIIIB-NA2 } \\
\text { allotype }^{\mathrm{c}} \text { among cerebral malaria patients, } \\
\text { when compared to mild malaria controls }\end{array}$ & $\begin{array}{l}\text { Omi et al, } \\
2002\end{array}$ \\
\hline Gambia & $\begin{array}{l}\text { Children aged } 0-10 \text { years with either } \\
\text { severe }(n=524) \text { or mild malaria }(n=333) \\
\text { and non-infected controls }(n=558)\end{array}$ & $\begin{array}{l}\text { Significant excess of } \mathrm{H} 131 / \mathrm{H} 131 \\
\text { homozygotes among severe malaria } \\
\text { patients, when compared to non-infected } \\
\text { controls }\end{array}$ & $\begin{array}{l}\text { Cooke et al, } \\
2003\end{array}$ \\
\hline Kenya & $\begin{array}{l}\text { Pregnant women, either HIV-1 positive ( } \mathrm{n} \\
=658) \text { or not }(\mathrm{n}=245) \text {, with }(\mathrm{n}=285) \text { or } \\
\text { without }(\mathrm{n}=618) \text { placental malaria }{ }^{\mathrm{d}} \text { at } \\
\text { delivery }\end{array}$ & $\begin{array}{l}\text { Significant excess of H131/H131 } \\
\text { homozygotes among HIV-1-positive } \\
\text { women (but not among HIV-1-negative } \\
\text { women) with placental malaria; similar } \\
\text { proportions of R131/R131 homozygotes in } \\
\text { both groups }\end{array}$ & $\begin{array}{l}\text { Brouwer et al, } \\
2004\end{array}$ \\
\hline
\end{tabular}

${ }^{a}$ High-risk infants had $\geq 30 \%$ of routine monthly blood smears positive for Plasmodium falciparum (parasite counts $>5000$ parasites per microlitre) over their first year of life.

${ }^{\mathrm{b}}$ Low-risk infants had $\leq 8 \%$ of routine monthly blood smears positive for Plasmodium falciparum (parasite counts $>5000$ parasites per microlitre) over their first year of life.

${ }^{\mathrm{c}}$ The Fc $\gamma$ RIIIB-NA2 allotype reduces the capacity for phagocytosis in neutrophils, when compared to the Fc $\gamma$ RIIIB-NA1 allotype (Salmon et al, 1990). The authors report no significant independent association between FcyRIIA or Fc $\gamma$ RIIIB allotypes and cerebral malaria; a significant association only emerged when the simultaneous carriage of $\mathrm{H} 131$ and NA2 alleles was considered.

${ }^{\mathrm{d}}$ Placental malaria was defined as the presence of malaria parasites in blood samples obtained, at delivery, from a shallow incision on the maternal side of the placenta. 
Therefore, H131/H131 homozygosity emerged as a risk factor for malaria morbidity in three different populationss, and R131/R131 homozygosity was associated with protection from high-density parasitaemia in one population. These unexpected findings could be tentatively explained as a consequence of an increased activation of the immune system, due to the engagement of Fc $\gamma$ RIIA-H131 by a broader repertoire of IgG subclasses, leading to the release of large amounts of pro-inflammatory cytokines and therefore to immunopathology and disease (Cooke et al, 2003). High frequencies of the H131 allele could have been maintained in malaria-exposed African populations as a result of a delicate balance between negative selection (due to the increased risk of severe malaria) and positive selection (due to reduced morbidity and mortality from infections with encapsulated bacteria) (Cooke et al, 2003). Alternatively, this may represent a spurious causal association resulting from linkage disequilibrium between the Fc $\gamma$ RIIA-H131 allotype and other genetic determinants of malaria morbidity.

Further speculations are limited by the lack of more appropriate data. No longitudinal study, for example, has so far examined the combined effects of H/R131 Fc $\gamma$ RIIA polymorphism and levels of $\mathrm{IgG}_{2}$ antibodies to malarial antigens upon malaria morbidity. Polymorphisms in other linked genes, such as Fc $\gamma$ RIIIB, should be examined and adjusted for in risk analysis. Age represents an important factor: infants are less likely to benefit from the ability of the Fc $\gamma$ RIIA-H131 allotype to bind malaria parasitespecific $\mathrm{IgG}_{2}$ than older children and adults, since they tend to produce low levels of antibodies of this subclass in response to antigenic stimuli (Bird et al, 1985). Adult concentrations of $\mathrm{IgG}_{2}$ are usually reached at the age of 10 years (Maguire et al, 2002), but children living in areas of intense malaria transmission are already clinically immune and rarely experience severe disease at this age (Day and Marsh, 1991). Experimental murine malaria models cannot provide valuable information, as no Fc $\gamma$ RIIA homologue has been found in the mouse (Gessner et al, 1998).

\section{CONCLUSIONS}

Three case-control studies revealed weak but significant associations between H131/H131 homozygosity and increased $P$. falciparum morbidity in different populations (Omi et al, 2002; Cooke et al, 2003; Brouwer et al, 2004), while one study suggested that R131/R131 homozygosity may act as a protective factor against high-density parasitaemia (Shi et al, 2001). These results are at odds with the fact that R131 homozygotes cannot benefit from monocyte- or macrophage-mediated effector responses mediated by the binding of parasite-specific $\mathrm{IgG}_{2}$ antibodies to the H131 allotype of Fc $\gamma$ RIIA (Aucan et al, 2000). The origins of this apparent contradiction remain unclear; the fine balance between parasite-killing and pro-inflamatory effects of cytokines released by monocytes and macrophages, as a consequence of Fc $\gamma$ RIIA engagement by antiparasite antibodies of different IgG subclasses, may be involved. Additional studies are clearly needed to investigate the magnitude and direction of associations between Fc $\gamma$ RIIA polymorphism and malaria morbidity in popula- tions differing in genetic backgrounds and levels of acquired immunity to malaria parasites.

\section{ACKNOWLEDGEMENTS}

Reseach in our laboratories has been supported by grants from the Brazilian funding agencies Fundação de Amparo à Pesquisa do Estado de Minas Gerais (FAPEMIG), Fundação de Amparo à Pesquisa do Estado de São Paulo (FAPESP) and Conselho Nacional de Desenvolvimento Científico e Tecnológico (CNPq). KKGS, NTK, M da S$\mathrm{N}$ and MUF are recipients of scholarships from CAPES, Universidade de São Paulo, FAPESP and CNPq, respectively. We thank Estéfano Alves de Souza and Bruna de Almeida Luz (recipients of scholarships from CNPq and FAPESP, respectively) for their valuable help in data handling.

\section{STATEMENT OF COMPETING INTERESTS}

The authors declared no competing interests.

\section{LIST OF ABBREVIATIONS}

ADCC: antibody-dependent cell-mediated cytotoxicity

ADCI: antibody-dependent cellular inhibition

FcR: Fc receptor

FceE: receptor for immunoglobulin $\mathrm{E} F \mathrm{~F}$

$\mathrm{Fc} \gamma \mathrm{R}$ : receptor for immunoglobulin $\mathrm{G} \mathrm{Fc}$

$\mathrm{H}$ : histidine

Ig: immunoglobulin

NK: natural killer

pRBC: parasitised red blood cells

$\mathrm{R}$ : arginine

\section{REFERENCES}

Aucan C, Traoré Y, Tall F et al. 2000. High immunoglobulin G2 (IgG2) and low IgG4 levels are associated with human resistance to Plasmodium falciparum malaria. Infect Immun, $68,1252-1258$

Bird D, Duffy S, Isaacs D and Webster AD. 1985. Reference ranges for IgG subclasses in preschool children. Arch Dis Child, 60, 204-207.

Bouharoun-Tayoun H and Druilhe P. 1992. Plasmodium falciparum malaria: evidence for an isotype imbalance which may be responsible for delayed acquisition of protective immunity. Infect Immun, 60, 1473-1481.

Bouharoun-Tayoun H, Attanath P, Sabchareon A, Chongsuphajaisiddhi T and Druilhe P. 1990. Antibodies that protect humans against Plasmodium falciparum blood stages do not on their own inhibit parasite growth and invasion in vitro, but act in cooperation with monocytes. J Exp Med, 172, 1633-1641.

Bouharoun-Tayoun H, Oeuvray C, Lunel C and Druilhe P. 1995. Mechanisms underlying the monocyte-mediated antibody-dependent killing of Plasmodium falciparum asexual blood stages. J Exp Med, 182, 409-418.

Brouwer KC, Lal AA, Mirel LB et al. 2004. Polymorphism of Fc receptor IIa for immunoglobulin $\mathrm{G}$ is associated with placental malaria in HIV-1-positive women in Western Kenya. J Infect Dis, 190, 1192-1198.

Cooke GS, Aucan C, Walley AJ et al. 2003. Association of Fc $\gamma$ receptor IIa (CD32) polymorphism with severe malaria in West Africa. Am J Trop Med Hyg, 69, 565-568. 
Day KP and Marsh K. 1991. Naturally acquired immunity to Plasmodium falciparum. Parasitol Today, 7, 68-71.

Druilhe P and Pérignon JL. 1997. A hypothesis about the chronicity of malaria infection. Parasitol Today, 13, 353-357.

Ferrante A, Kumaratilake LM, Rzepczyk CM and Dayer J-M. 1990. Killing of Plasmodium falciparum by cytokine activated effector cells (neutrophils and macrophages). Immunol Letts, 25, 179-188.

Ferreira MU, Kimura EAS, Souza JM and Katzin AM. 1996. The isotype composition and avidity of naturally acquired anti-Plasmodium falciparum antibodies: differential patterns in clinically immune Africans and Amazonian patients. Am J Trop Med Hyg, 55, 315-323.

Flesch BK and Neppert J. 2000. Functions of the Fc receptors for immunoglobulin G. J Clin Lab Anal, 14, 141-156.

Gessner JE, Heiken H, Tamm A and Schidt RE. 1998. The IgG Fc receptor family. Ann Hematol, 76, 231-248.

Groux H and Gysin J. 1990. Opsonisation as an effector mechanism in human protection against asexual blood stages of Plasmodium falciparum: functional role of $\operatorname{IgG}$ subclasses. Res Immunol, 141, 529-542.

Guerin PJ, Olliaro P, Nosten, F et al. 2002. Malaria: current status of control, diagnosis, treatment, and a proposed agenda for research and development. Lancet Infect Dis, 2, 564-573.

Jansen WTM, Breukels MA, Snippe H, Sanders LAM, Verheul AFM and Rijkers GT. 1999. Fc $\gamma$ receptor polymorphism determine the magnitude of in vitro phagocytosis of Strptococcus pneumoniae mediated by pneumococcal conjugate sera. J Infect Dis, 180, 888-891.

Karassa F, Trikalinos TA and Ioannidis JPA. 2004. The role of FCrRIIA and IIIA polymorphisms in autoimmune diseases. Biomed Pharmacol, 58, 286-291.

Kinet J-P. 1999. The high-affinity IgE receptor (FceRI): from physiology to pathology. Annu Rev Immunol, 17, 931-972.

Kuwano ST, Bordin JO, Chiba AK et al. 2000. Allelic polymorphisms of human Fcy receptor II $a$ and Fcy receptor IIIb among distinct groups in Brazil. Transfusion, 40, 1388-1392.

Lehrnbecher T, Foster CB, Zhu S et al. 1999. Variant genotypes of the low-affinity $\mathrm{Fc} \gamma$ receptors in two control populations and a review of low-affinity Fc $\gamma$ receptor polymorphisms in control and disease populations. Blood, 94, 42204232.

Maguire GA, Kumararatne DS and Joyce HJ. 2002. Are there any clinical indications for measuring IgG subclasses? Ann Clin Biochem, 39, 374-377.

Monteiro RC and van der Winkel JGJ. 2003. IgA Fc receptors. Annu Rev Immunol, 21, 177-204.

Omi K, Ohashi J, Patarapotikul J et al. 2002. Fcr receptor IIA and $I I I B$ polymorphisms are associated with susceptibility to cerebral malaria. Parasitol Int, 51, 361-366.

Ravetch JV and Bolland S. 2001. IgG Fc receptors. Annu Rev Immunol, 19, 275-290.

Rodríguez ME, van der Pol WL, Sanders LAM and van der Winkel JGJ. 1999. Crucial role of FcyRIIa (CD32) in assessment of functional anti-Streptococcus pneumoniae antibody activity in human sera. J Infect Dis, 179, 423-433.

Salmon JE, Edberg JC and Kimberly RP. 1990. Fc $\gamma$ receptor III on human neutorphils. Allelic variants have functionally distinct capacities. J Clin Invest, 85, 1287-1295.

Salmon JE, Millard S, Schachter LA et al. 1996. FcyRIIA alleles are heritable risk factors for lupus nephritis in African Americans. J Clin Invest, 97, 1348-1354.

Sanders LAM, Feldman RG, Voorhorst-Ogink MM et al. 1995. Human immunoglobulin $\mathrm{G}$ ( $\mathrm{IgG})$ Fc $\gamma$ RIIA (CD32) polymorphism and $\mathrm{IgG}_{2}$-mediated bacterial phagocytosis by neutrophils. Infect Immun, 63, 73-81.

Shi YP, Nahlen BL, Kariuki S et al. 2001. Fc $\gamma$ receptor IIa (CD32) polymorphism is associated with protection of in- fants against high-density Plasmodium falciparum infection. VII. Asembo Bay Cohort Project. J Infect Dis, 184, 107111.

$\mathrm{Su} \mathrm{K}, \mathrm{Wu}$ J, Edberg JC, McKenzie SE and Kimberly RP. 2002. Genomic organisation of classical human low-affinity Fcgamma receptor genes. Genes Immun, 3, S51-S56.

Tebo AE, Kremsner PG and Luty JF. 2002. Fcy receptormediated phagocytosis of Plasmodium falciparum-infected erythrocytes in vitro. Exp Parasitol, 130, 300-306.

Wahlgren M, Berzins K, Perlman P and Persson M. 1983. Characterisation of the humoural immune response in Plasmodium falciparum malaria. II. IgG subclass levels of anti$P$. falciparum antibodies in different sera. Clin Exp Immunol, 54, 135-142.

Warmerdam PAM, van der Winkel JG, Gosselin EJ and Capel PJ. 1990. Molecular basis for a polymorphism of human FcrRII (CD32). J Exp Med, 172, 19-25.

\section{SHORT COPYRIGHT STATEMENT}

This is an open access article, published under the terms of the Licence for Users available at http://www.libpubmedia.co.uk/ MedJ/LicenceForUsers.pdf. This licence permits noncommercial use, distribution and reproduction of the article, provided the original work is appropriately acknowledged with correct citation details. 